\title{
Efficiency of four secondary enrichment protocols in differentiation and isolation of Listeria spp. and Listeria monocytogenes from smoked fish processing chains
}

\author{
Gabriela Duarte $^{\mathrm{a}, *}$, Manuela Vaz-Velho ${ }^{\mathrm{a}, \mathrm{b}}$, Christopher Capell ${ }^{\mathrm{a}}$, Paul Gibbs ${ }^{\mathrm{a}, \mathrm{c}}$ \\ ${ }^{a}$ Escola Superior de Biotecnologia, Universidade Católica Portuguesa, Rua Dr. António Bernardino de Almeida, 4200 Porto, Portugal \\ ${ }^{\mathrm{b}}$ Escola Superior de Tecnologia e Gestão, Instituto Politécnico de Viana do Castelo, Porto, Portugal \\ ${ }^{\mathrm{c}}$ Leatherhead Food Research Association, Surrey, UK
}

\begin{abstract}
Four secondary enrichment protocols (conventional methods: UVM II, Fraser $24 \mathrm{~h}$ and Fraser 48 h: Impedimetric method: Listeria electrical detection medium) were studied for their ability to isolate Listeria spp. and Listeria monocytogenes from fish and environmental samples collected along the processing chain of cold-smoked fish. From all methods, Listeria spp. and L. monocytogenes were respectively present in 56 and 34 of 315 samples analysed. Fraser broth incubated for $48 \mathrm{~h}$ gave the fewest false negative Listeria spp. results [4/56; $(7.1 \%)$, but concurrently only $15 / 34(44.1 \%)$ samples were correctly identified as containing L. monocytogenes. Listeria electrical detection (LED) medium detected only 36/56 (64.3\%) Listeria spp. positive samples. Despite this lower isolation rate, LED identified 20/34 (58.8\%) L. monocytogenes positive samples correctly and gave fewer false positive results. The overall conclusion was that more than one isolation method is needed to accurately estimate L. monocytogenes contamination rates.
\end{abstract}

Keywords: Cold-smoked fish; Listeria; Listeria monocytogenes; Secondary selective enrichments; Conventional cultural and bactometer capacitance-based detection methods

\section{Introduction}

The genus Listeria includes six species: L. monocytogenes, L. innocua, L. seeligeri, L. ivanovii, $L$. welshimeri and L. grayi (Lovett and Twedt, 1988;

\footnotetext{
*Corresponding author. Tel.: +351-2-5580-043; fax: +351-25090-351.

E-mail address: gabi@morango.esb.ucp.pt (G. Duarte)
}

Rocourt et al., 1992). The ingestion of L. monocytogenes in foods can pose a significant health risk, with a high reported mortality rate for foetuses and immunocompromised patients.

Is important to prevent the contamination of ready-to-eat products, like cold-smoked fish, with $L$. monocytogenes. The mild temperatures $\left(<30^{\circ} \mathrm{C}\right)$ and low brine concentrations $(\mathrm{NaCl}, \%$ in aqueous phase ca. $3.5 \%$ ) used in the cold-smoking process are not sufficient to inactivate $L$. monocytogenes or 
to limit growth of the organism in the product during storage.

Traditional isolation methods for Listeria spp. from foods take more than one week to complete. For a food company operating a positive release system this leads to lengthy delays before the product is known to be "safe". As a result, there has been interest in developing sensitive and rapid methods for detecting L. monocytogenes in foods. Development of fully automated immunological and genetic based methods which are suitable for routine monitoring of food products has been made, though the balance between accuracy, time and the corresponding cost does not always make implementation of these methods commercially worthwhile.

This study was conducted to evaluate the efficacy of individual selective secondary enrichment protocols, three traditional growth media and a bactometer-based capacitance broth, for presumptive differentiation and isolation of Listeria spp. from environmental and fish samples taken from salmon, salmon-trout, tuna fish and swordfish cold-smoked processing chains.

\section{Materials and methods}

During a one-year period, a total of 183 fish samples and 132 environmental samples were collected from the production chain of three Portuguese cold-smoking factories and examined for Listeria spp. and L. monocytogenes.

The methodology of Rodrigues et al. (1995) and Capell et al. (1995) for Listeria isolation from food products, using UVM I as primary enrichment medium, Fraser and Listeria electrical detection (LED) broths as secondary enrichment media and selective plating on Oxford agar, was combined with the Jemmi and Keusch (1994) procedure for Listeria detection in the cold-smoked fish processing chain using UVM I and UVM II enrichment steps with isolation on Oxford and PALCAM agars. Swabs from fresh salmon and salmon trout skin, from eviscerated fresh salmon belly cavity and from working surfaces $\left(10 \mathrm{~cm}^{2}\right.$, five swabs per sample) were placed in $25 \mathrm{ml}$ of $0.1 \%(\mathrm{w} / \mathrm{v})$ peptone water [tryptone, $1 \mathrm{~g} / 1$ (Lab M MC5, Bury, UK); NaCl 5 g/l (Merck 6404, Darmstadt, Germany)] and trans- ported to the laboratory in chilled boxes and then transferred to $225 \mathrm{ml}$ of UVM I (Merck $110824.0500)$. Water and ice samples $(500 \mathrm{ml})$ were filtered $(0.45 \mu \mathrm{l}$ sterile membrane filters, $\varnothing 47 \mathrm{~mm}$, Gelman Sciences, MI, USA) and the filters were placed in $20 \mathrm{ml}$ of UVM I. A $25 \mathrm{~g}$ amount of processed fish and fish feed was placed in $225 \mathrm{ml}$ of UVM I and homogenised in a stomacher for $2 \mathrm{~min}$. All the UVM I samples were incubated at $30^{\circ} \mathrm{C}$ for $24 \mathrm{~h}$ and an aliquot $(0.1 \mathrm{ml})$ then transferred to 10 $\mathrm{ml}$ of two secondary enrichment broths, UVM II [UVM I + $0.013 \mathrm{~g} / 1$ acriflavine $\mathrm{HCl}$ (Sigma A8251, Aldrich, Madrid, Spain)] and Fraser broth (Merck 110398.0500 ), and incubated at $30^{\circ} \mathrm{C}$ for $24 \mathrm{~h}$ and 24-48 h, respectively. At the same time, $0.05 \mathrm{ml}$ of the UVM I samples was added to $2 \mathrm{ml}$ of LED medium (Rodrigues et al., 1995) that had been prewarmed to $30^{\circ} \mathrm{C}$ in bactometer module wells (BioMérieux 99052, BioMérieux Vitek, MO, USA). The modules were placed into the Vitek bactometer (Model 120 SC, BioMérieux Vitek), set to monitor capacitance for a test time of $48 \mathrm{~h}$ at $30^{\circ} \mathrm{C}$. The samples showing presumptive positive characteristics (turbidity in UVM II, darkening in Fraser broth after $24 \mathrm{~h}$ or $48 \mathrm{~h}$, and more than $30 \%$ change in capacitance within $30 \mathrm{~h}$ in LED medium measured by the bactometer) were considered as presumptive positives. All the samples. whether showing growth or not, were subcultured onto Oxford (Merck 107004.0500) and PALCAM (Merck 11755.0500) agars by streaking and incubated at $30^{\circ} \mathrm{C}$ for $48 \mathrm{~h}$. Colonies presenting typical Listeria spp. characteristics were streaked on the tryptone soy yeast extract agar (TSAYE) [tryptone soy broth (Lab M LAB4) + $6 \mathrm{~g} / 1$ yeast extract $(\mathrm{Lab} \mathrm{M} \mathrm{MCl})+12 \mathrm{~g} / 1$ agar $(\mathrm{Lab}$ $\mathrm{M} \mathrm{MC2}$ )] and incubated at $37^{\circ} \mathrm{C}$ for $24 \mathrm{~h}$, before further confirmation tests.

All the isolates were confirmed to the genus level by Gram staining, catalase and oxidase tests and tumbling motility (tryptone soy broth, $22^{\circ} \mathrm{C}, 24 \mathrm{~h}$ ), and to the species level by API Listeria (BioMérieux 10300) and the CAMP (Christie et al., 1944, cit. Farber and Peterkin, 1991) test with Staphylococcus aureus ATCC 25923 (Food Quality Centre, Escola Superior de Biotecnologia, Porto, Portugal) and Rhodococcus equi NCTC 1691 [Leatherhead Food Research Association (LFRA), Surrey, UK] on sheep blood agar plates (BioMérieux 43041). 


\section{Results and discussion}

Four secondary enrichment methods for Listeria spp. detection (three conventional and one electrical capacitance method) were simultaneously performed on 183 fish samples and 132 environmental samples.

The sample was considered positive whenever it was confirmed positive in one or more media and negative only if it was confirmed to be negative in all the media simultaneously.

Listeria spp. and L. monocytogenes were isolated from 56 and 34 of 315 fish and environmental samples, respectively.

The results from the environmental samples are shown in Table 1.

From a total of 132 samples, nine (7\%) contained Listeria spp. Six of the nine positive samples (66.7\%) contained only L. monocytogenes and three samples $(33.3 \%)$ contained both L. monocytogenes and L. innocua.

The sensitivity [correct positives rate $(\%)=$ correct positives/(correct positives + false negatives); Flanders et al., 1995] of the four protocols was the same (6/9). The number of false presumptive negative results $(3 / 9)$ obtained was also the same for the four protocols. Considering the individual analysis of each protocol, LED broth showed the highest specificity giving the lowest number of false positive results (32/123). UVM II, the least specific medium, gave the highest number of false positive results (84/123). Fraser $24 \mathrm{~h}$ and 48 $\mathrm{h}$ broths gave 48/123 and 53/123 false positive results, respectively.

The results from the fish samples are included in Table 1.

From the 183 fish samples, 47 (25.7\%) were

Table 1

Detection of Listeria spp. in environmental (E.S.) and fish samples (F.S.) from production lines of cold-smoked fish ${ }^{\mathrm{a}}$

\begin{tabular}{|c|c|c|c|c|c|c|}
\hline \multirow[t]{3}{*}{ Protocol } & \multicolumn{4}{|c|}{ Single protocol results ${ }^{\mathrm{b}}$} & \multirow{2}{*}{\multicolumn{2}{|c|}{$\begin{array}{l}\text { Combined results }^{\mathrm{c}} \\
\text { Confirmed positives/ } \\
\text { total positives }\end{array}$}} \\
\hline & \multicolumn{2}{|c|}{$\begin{array}{l}\text { Confirmed as } \\
\text { correct }\end{array}$} & \multicolumn{2}{|c|}{$\begin{array}{l}\text { Confirmed as } \\
\text { incorrect }\end{array}$} & & \\
\hline & E.S. & F.S. & E.S. & F.S. & E.S & F.S. \\
\hline \multicolumn{7}{|c|}{ UTVM II } \\
\hline P.P. & $6 / 90^{\mathrm{d}}$ & $41 / 176^{d}$ & $84 / 90^{\mathrm{e}}$ & $135 / 176^{\mathrm{e}}$ & $6 / 9^{f}$ & $47 / 47^{1}$ \\
\hline P.N. & $42 / 42^{\mathrm{g}}$ & $7 / 7^{\mathrm{g}}$ & $0 / 42^{\mathrm{h}}$ & $0 / 7^{\mathrm{h}}$ & $3 / 9^{i}$ & $0 / 47^{\mathrm{i}}$ \\
\hline \multicolumn{7}{|c|}{ Fraser $24 \mathrm{~h}$} \\
\hline P.P. & $6 / 54^{\mathrm{d}}$ & $44 / 133^{d}$ & $48 / 54^{\mathrm{e}}$ & $89 / 133^{e}$ & $6 / 9^{f}$ & $45 / 47^{1}$ \\
\hline P.N. & $78 / 78^{\mathrm{g}}$ & $50 / 50^{\mathrm{g}}$ & $0 / 78^{\mathrm{h}}$ & $0 / 50^{\mathrm{h}}$ & $3 / 9^{i}$ & $2 / 47^{\mathrm{i}}$ \\
\hline \multicolumn{7}{|c|}{ Fraser $48 \mathrm{~h}$} \\
\hline P.P. & $6 / 59^{d}$ & $45 / 136^{\mathrm{d}}$ & $53 / 59^{\mathrm{e}}$ & $91 / 136^{\mathrm{e}}$ & $6 / 9^{f}$ & $46 / 47^{1}$ \\
\hline P.N. & $73 / 73^{\mathrm{g}}$ & $47 / 47^{\mathrm{g}}$ & $0 / 73^{\mathrm{h}}$ & $0 / 47^{\mathrm{h}}$ & $3 / 9^{i}$ & $1 / 47^{\mathrm{i}}$ \\
\hline \multicolumn{7}{|l|}{$L E D$} \\
\hline P.P. & $6 / 38^{\mathrm{d}}$ & $30 / 66^{d}$ & $32 / 38^{\mathrm{e}}$ & $36 / 66^{\mathrm{e}}$ & $6 / 9^{f}$ & $31 / 47^{\prime}$ \\
\hline P.N. & $93 / 94^{g}$ & $107 / 117^{\mathrm{g}}$ & $1 / 94^{\mathrm{h}}$ & $10 / 117^{\mathrm{h}}$ & $3 / 9^{i}$ & $16 / 47^{i}$ \\
\hline
\end{tabular}

${ }^{\mathrm{a}} \mathrm{P} . \mathrm{P}$. $=$ Presumptive positives; P.N. = presumptive negatives.

${ }^{\mathrm{b}}$ Individual analysis of each protocol.

${ }^{\mathrm{c}}$ Simultaneous analysis of the four protocols.

${ }^{\mathrm{d}}$ Correctly identified and confirmed presumptive positive results after isolation on Oxford and/or PALCAM.

${ }^{\mathrm{e}}$ Total presumptive positive results confirmed to be negatives after isolation on Oxford and PALCAM.

${ }^{\mathrm{f}}$ Total presumptive positive results confirmed as positive by any of the methods.

${ }^{g}$ Correctly identified presumptive negative results after isolation on Oxford and PALCAM.

${ }^{\text {h }}$ Presumptive negative results subsequently confirmed to be positive after isolation on Oxford rind/or PALCAM.

${ }^{\mathrm{i}}$ Total presumptive negative results subsequently confirmed to be positive by any of the methods. 
confirmed positive for Listeria spp. Thirteen of these 47 positive samples $(27.7 \%)$ contained only $L$. innocua; five (10.6\%) contained only L. monocytogenes; $20(42.6 \%)$ contained both L. monocytogenes and L. innocua. In addition, five samples (10.6\%), three samples $(6.4 \%)$ and one sample $(2.1 \%)$ contained only $L$. seeligeri, both $L$. innocua and $L$. welshimeri, and both L. innocua and L. seeligeri, respectively.

In terms of sensitivity, LED broth was poor, giving the highest number of false negative results (16/47). However, LED broth exhibited the highest specificity [correct negatives rate $(\%)=$ correct negatives/(correct negatives + false positives); Flanders et al., 1995] with the smallest number of false positive results (36/136). Fraser $24 \mathrm{~h}$ and $48 \mathrm{~h}$ broths gave 88/136 and 91/136 false positive results and $2 / 47$ and $1 / 47$ false negative results, respectively. UVM II presented the lowest specificity giving the highest number of false positives $(135 / 136)$ but no $(0 / 47)$ false negative results. Despite Listeria spp. being isolated from 40 of the LED method tests, the bactometer only gave $31 / 47$ curves with $30 \%$ change within $30 \mathrm{~h}$ but no Listeria spp. were isolated from one of these presumptive positive LED broths that was confirmed as being positive by other methods; further 10 LED tests, from which Listeria spp. were isolated, were considered as presumptive negatives as they gave either less than $30 \%$ change in capacitance after $3 \mathrm{~h}$ or atypical curves.

The LED method seems to be the best method for environmental samples showing the highest specificty. The reduction in false presumptive positives was achieved without increasing the number of false negatives and the presumptive positive results could be obtained up to $18 \mathrm{~h}$ before the traditional methods.

The LED method appears unsuitable for screening of fish samples, due to the high number of false negative results (curves $<30 \%$ change within $30 \mathrm{~h}$ ). UVM II, although giving no false negative results, seems not to be appropriate as a differential medium, since it gave 219/259 false positive results (using turbidity as a presumptive test). Despite producing 91/136 false positive results for fish samples, Fraser $48 \mathrm{~h}$ broth gave a low number of false negative results $(1 / 47)$ which makes it the elective method of choice for these types of products. This $66 \%$ false presumptive positive rate is similar to other reported results for Fraser broth with other foods $(70.7 \%$, Warburton et al., 1991; 65.5\%, Rodrigues et al., 1995). Commercial application of expensive rapid confirmation techniques to Fraser $48 \mathrm{~h}$ broth would suffer from the high false presumptive positive rate.

The isolation rates of $L$. monocytogenes were not equal between the four secondary enrichment protocols (Tables 2 and 3). More than one species was isolated from $26(46 \%)$ of the 56 samples found to contain Listeria spp. Despite having the lowest Listeria spp. isolation rate, LED medium gave the highest isolation rate of L. monocytogenes.

Ravomanana and Rosec (1993) examined 140 food samples and found Fraser enrichment to be more effective and rapid, giving more positive results for both L. monocytogenes and Listeria spp. after both $24 \mathrm{~h}$ and $48 \mathrm{~h}$ incubation than UVM II. Kornacki et al. (1993) compared the recovery of $L$. monocytogenes from Fraser broth incubated for $26 \mathrm{~h}$ versus $48 \mathrm{~h}$ and found $3.3 \%$ false negative results at $26 \mathrm{~h}$. In the study of Walker et al., (1990), $23 \%$ of

Table 2

Identification of L. monocytogenes from test samples found to contain Listeria species

\begin{tabular}{lllll}
\hline Protocol & Oxford & PALCAM & Either agar & Both agars \\
\hline UVM II & $14 / 47$ & $19 / 46$ & $20 / 47$ & $13 / 46$ \\
Fraser 24 h & $12 / 50$ & $11 / 49$ & $17 / 50$ & $6 / 48$ \\
Fraser 48 h & $11 / 51$ & $12 / 51$ & $15 / 51$ & $8 / 51$ \\
LED (all isolates) & $24 / 46$ & $19 / 46$ & $15 / 47$ & $18 / 45$ \\
LED (only presumptive positives) & $19 / 35$ & $16 / 35$ & $20 / 36$ & $5 / 34$ \\
Total confirmed & $31 / 56(55 \%)$ & $30 / 56(54 \%)$ & $34 / 56(61 \%)^{\mathrm{a}}$ & $24 / 56(43 \%)^{\mathrm{b}}$ \\
L. monocytogenes & & & & $5 / 56(9 \%)^{\mathrm{c}}$ \\
\hline
\end{tabular}

\footnotetext{
${ }^{a}$ Confirmed L. monocytogenes result from any plate of any test.

${ }^{\mathrm{b}}$ Confirmed L. monocytogenes result from both plates of any test.

${ }^{\mathrm{c}}$ Confirmed L. monocytogenes result from all plates of all protocols.
} 
Table 3

Species composition of the 56 Listeria spp. positive samples

\begin{tabular}{|c|c|c|c|c|c|c|}
\hline Agar & Protocol & L. monocytogenes & L. innocua & L. seeligeri & L. welshimeri & Totals \\
\hline \multirow[t]{4}{*}{ Oxford } & UVM II & 14 & 29 & 4 & 0 & $47 / 56$ \\
\hline & Fraser $24 \mathrm{~h}$ & 12 & 29 & 7 & 2 & $50 / 56$ \\
\hline & Fraser $48 \mathrm{~h}$ & 11 & 32 & 6 & 2 & $51 / 56$ \\
\hline & LED & $24(19)^{\mathrm{a}}$ & $16(14)^{\mathrm{a}}$ & $5(1)^{\mathrm{a}}$ & $1(1)^{a}$ & $46(35)^{a} / 56$ \\
\hline \multirow[t]{4}{*}{ PALCAM } & UVM II & 19 & 20 & 5 & 2 & $46 / 56$ \\
\hline & Fraser $24 \mathrm{~h}$ & 11 & 32 & 5 & 2 & $49 / 56$ \\
\hline & Fraser $48 \mathrm{~h}$ & 12 & 31 & 6 & 2 & $51 / 56$ \\
\hline & LED & $19(16)^{\mathrm{a}}$ & $21(17)^{\mathrm{a}}$ & $4(0)^{\mathrm{a}}$ & $2(2)^{\mathrm{a}}$ & $46(35)^{a} / 56$ \\
\hline
\end{tabular}

a Only bactometer "typical curves" ( $>30 \%$ a change in capacitance in $<30 \mathrm{~h}$ ).

the samples that were positive in Fraser after $48 \mathrm{~h}$ incubation were negative after only $24 \mathrm{~h}$. In our study, one extra Listeria spp. positive sample was found after $48 \mathrm{~h}$ in Fraser broth. However, after $48 \mathrm{~h}$, fewer identifications of the presence of L. monocytogenes were made from Oxford or PALCAM agars (Table 2, $24 \mathrm{~h}: 17 / 50,48 \mathrm{~h}: 15 / 51$ ). This result could be due to the variability resulting from confirmation of only one colony from each Oxford and PALCAM agar from each secondary enrichment medium. The overgrowth of L. monocytogenes by other Listeria spp. is a more probable explanation, as the two samples identified as containing L. monocytogenes after $24 \mathrm{~h}$ but not after $48 \mathrm{~h}$ were identified as containing L. innocua after $48 \mathrm{~h}$.

Patel and Beuchat (1995) reported Fraser broth to show lower recovery of heat-injured Listeria spp., probably due to the presence of lithium chloride. In the LED medium, the concentration of lithium chloride $(1.75 \%)$ is nearly six-times higher than in Fraser broth. Even so, greater isolation rates of $L$. monocytogenes were obtained from LED than from the other broths when plated onto Oxford and PALCAM agars. Moreover, Cox et al. (1997) found that L. monocytogenes could grow at concentrations up to $2 \% \mathrm{LiCl}$, but above this level inhibition occurred.

MacDonald and Sutherland (1994), using an impedance technique for Listeria detection, never found L. innocua and L. monocytogenes in the same milk sample, and when they inoculated both species together into the same sample, $L$. innocua outgrew $L$. monocytogenes. In the present study, both species were found together in 23 samples. Curiale and Lewus (1994), reported that L. innocua has a shorter generation time than $L$. monocytogenes and that recovery of $L$. monocytogenes from foods using selective broths was lower when $L$. innocua was present. Beumer et al. (1997) stated that enrichment broths having lower acriflavine concentrations and an adequate buffer favoured the isolation of L. monocytogenes. The LED medium contained half the acriflavine concentration of UVM II and Eraser broths. As shown in Table 3, the LED medium recovered more L. monocytogenes than L. innocua. The other broths recovered more $L$. innocua than $L$. monocytogenes which suggests the incidence of $L$. monocytogenes to be underestimated when only high acriflavine media are used and if samples contain both these Listeria spp.

The present results. as well as those from several other studies, make it clear that no enrichment broth by itself can assure a $100 \%$ recovery rate of Listeria spp. or more significantly L. monocytogenes. In this study, only 39 of the 56 Listeria spp. confirmed positive samples (at least positive by one method) were simultaneously positive by all methods examined.

Although L. monocytogenes was found in 34 samples after isolation from either Oxford or PALCAM agars, only five samples (Table 3) were simultaneously positive in all the protocols. If the isolation on either of the selective agars was considered, only nine samples would be simultaneously positive for L. monocytogenes in all four broths. These differences between methods underline the probability of underestimation of the occurrence of L. monocytogenes when just one protocol is used for its detection. Rather than promoting a single method for detection of Listeria spp. and L. monocytogenes, 
the benefit of using a combination of methods should be stressed.

\section{Acknowledgements}

The FAIR project CT95-1207 "Spoilage and Safety of Cold-Smoked Fish" and JNICT for the financial support of Gabriela Duarte, are gratefully acknowledged.

\section{References}

Beumer, R.R., Giffel. M.C., Anthonie, S.V.R., Cox. L.J., 1997. The effect of acriflavine and nalidixic acid on the growth of Listeria spp. in enrichment media. In: Beumer, R.R. (Ed.), Listeria monocytogenes - Detection and Behaviour in Food and Environment. Thesis Landbouwuniversiteit Wageningen. Koninklijke Bibliotheek, Den Haag, pp. 35-54.

Capell, C.J., Kirby, R.M., Moss, M.O., 1995. A method and medium for the electrical detection of Listeria spp. from food. Int. J. Food Microbiol. 25, 169-177.

Cox, L.J., Dooley, D., Beumer, R.R., 1997. Effect of lithium chloride and other inhibitors on the growth of Listeria spp. In: Beumer, R.R. (Ed.), Listeria monocytogenes - Detection and Behaviour in Food and Environment, pp. 17-34.

Curiale, M., Lewus, C., 1994. Detection of Listeria monocytogenes in samples containing Listeria innocua. J. Food Prot. 57, 1048-1051.

Flanders, K., Pritchard, T., Donnely, C., 1995. Enhanced recovery of Listeria from dairy-plant processing environments through combined use of repair enrichment and selective enrichment/ detection procedures. J. Food Prot. 58, 404-409.
Jemmi, T., Keusch, A., 1994. Occurrence of Listeria monocytogenes in freshwater fish farms and fish-smoking plants. Food Microbiol. 11, 306-309.

Kornacki, J., Evanson, D., Reid, W., Rowe, K., Flowers, S., 1993. Evaluation of the USDA protocol for detection of Listeria monocytogenes. J. Food Prot. 56, 441-443.

Lovett, J., Twedt, R., 1988. Listeria. Food Technol. April, 188191.

MacDonald, F., Sutherland, A., 1994. Important differences between generation times of Listeria monocytogenes and Listeria innocua in two Listeria enrichment broths. J. Dairy Res. 61, 433-436.

Patel, J., Beuchat, L., 1995. Evaluation of enrichment broths for their ability to recover heat-injured Listeria monocytogenes. J. Appl. Bacteriol. 78, 366-372.

Ravomanana, D., Rosec, J., 1993. Étude comparative de trois protocoles de recherche de Listeria spp. et Listeria monocytogenes dans les produits alimentaires. Actualités Tech. Industrielles, IAA October, 730-732.

Rocourt, J., Boerlin, P., Grimont, F., Jacquet, C., Piffaretti, J.C., 1992. Assignment of Listeria gravi and Listeria murrayi to a single species, Listeria grayi, with a revised description of Listeria grayi. Int. J. Syst. Bacteriol. 42, 171-174.

Rodrigues, M.J., Capell, C.J., Kirby, R.M., 1995. A new capacitance medium for presumptive detection of Listeria spp. from cheese samples. J. Microbiol. Methods 23, 291-296.

Walker, S., Archer, P., Appleyard, J., 1990. Comparison of the Listeria-Tek ELISA kit with cultural procedures for the detection of Listeria species in foods. Food Microbiol. 7, 335-342.

Warburton, D., Farber, J., Armstrong, A., Caldeira, R., Tiwari, N., Babiuk, T., Lacassce, P., Read, S., 1991. A Canadian comparative study of modified versions of the FDA and USDA methods for the detection of Listeria monocytogenes. J. Food Prot. 54 669-676. 